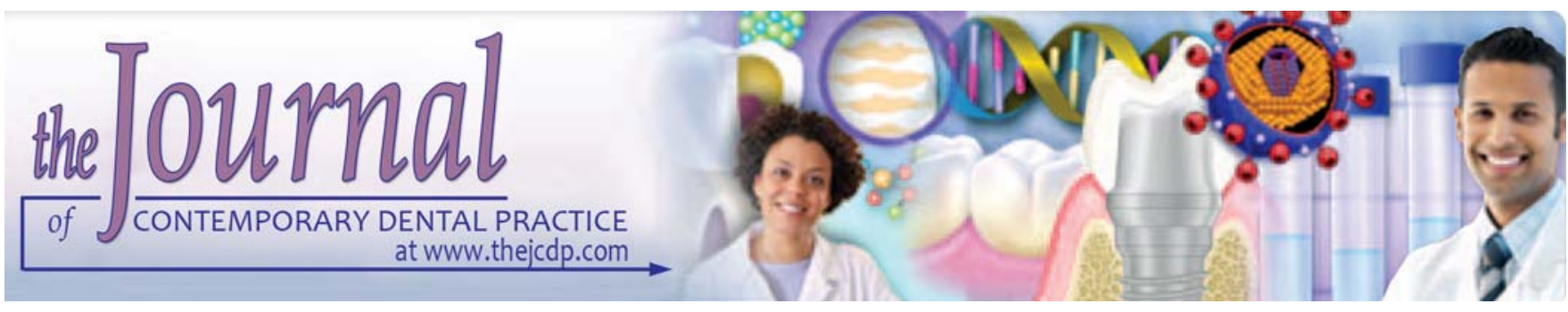

\title{
An Experimental Study of Arch Perimeter and Arch Width Increase with Mandibular Expansion: A Finite Element Method
}

Baswaraj, M Hemanth, Jayasudha, Chandrashekhargouda Patil, P Sunilkumar, HP Raghuveer, B Chandralekha

\section{ABSTRACT}

Aims: The objective of this study was to estimate the increase in arch perimeter associated with mandibular lateral expansion, To estimate the increase in intermolar width with mandibular lateral expansion and to find out the changes of tooth inclination with mandibular expansion.

Materials and methods: The mandibular bone with dentition of indian skeletal specimen was obtained. The computer tomogram (CT) slices of the mandible were taken. Finite element model (FEM): Numerical representation of the geometry was created by dividing the geometry into finite number of elements and the elements were connected together with nodes at the junction.

Results: The result of the study showed when $10^{\circ}$ of lateral expansion was applied to the lower buccal segment at the center of rotation found at $4.3 \mathrm{~mm}$ below the root apex of first molar, a space of $1.3 \mathrm{~mm}$ between the canine and first premolar, and thus an increase in arch perimeter of $2.6 \mathrm{~mm}$.

Conclusion: The tip of the mesiolingual cusp of the first molar moved $4.2 \mathrm{~mm}$ laterally, resulting in a change in intermolar width by $8.4 \mathrm{~mm}$. Three-dimensional simulation showed that $1 \mathrm{~mm}$ of intermolar expansion increased the arch perimeter by $0.30 \mathrm{~mm}$.

Clinical significance: As the finite element method evolves and scientists are able to more clearly define physical properties of biological tissues, more accurate information can be generated at the level that other analytical methods cannot fully provide data. This result would be of value clinically for prediction of the effects of mandibular expansion.

Keywords: Mandibular expansion, CT scan, Finite element method, Center of rotation, Arch width, Arch perimeter.

How to cite this article: Baswaraj, Hemanth $M$, J ayasudha, Patil C, Sunilkumar P, Raghuveer HP, Chandralekha B. An Experimental S tudy of Arch Perimeter and Arch W idth Increase with Mandibular Expansion: A Finite Element Method. J Contemp Dent Pract 2013;14(1):104-110.

\section{Source of support: $\mathrm{Ni}$}

Conflict of interest: None declared

\section{INTRODUCTION}

The current trends in the practice of orthodontics have shifted toward the principles of dentofacial orthopedics and nonextraction treatment modalities. ${ }^{1}$ A Ithough extraction/ nonextraction arguments in orthodontics have continued over a long period, during the past decade, there has been a renewed interest in providing routine relief of crowding without premolar extractions. ${ }^{2}$ In a borderline case, expansion can be used to solve the space deficiency problem and treat the malocclusion without extraction, if the patient's conditions permit the expansion. The prediction of arch perimeter change for a given amount of expansion is hel pful in planning the treatment of patients who need expansion, and it can facilitate nonextraction orthodontic treatment. ${ }^{3}$

Finite el ement method (FEM) is a powerful contemporary research tool. The three-dimensional FEM used in the present study provides the freedom to simulate orthodontic force systems applied clinically and allows analysis of response of the dentoal veolar system to the orthodontic loads in three-dimensional space. The point of application, magnitude and direction of the force may easily be varied to simulate the clinical situation. Thus, FEM would be an effective approach in an investigation of the increase in arch perimeter with mandibular expansion in three-dimensions. Initial tooth displacements may be studied in relation to their skeletal environment. $V$ ariable force systems that can be accurately measured may be applied without altering the anatomic geometry.

Therefore, the purpose of this study was to find out the increase in arch perimeter, intermolar width and changes in tooth inclination associated with mandibular expansion by FEM. 
The aims and objectives are as follows:

1. To estimate the increase in arch perimeter associated with mandibular lateral expansion.

2. To estimate the increase in intermolar width with mandibular lateral expansion.

3. To find out the changes of tooth inclination with mandibular expansion.

\section{MATERIALS AND METHODS}

The mandibular bone with dentition of indian skeletal specimen was obtained from the Department of A natomy, $B$ angalore Medical College, Bengaluru. The computer tomogram (CT) slices of the mandible were taken from Department of Radiology, NIM HANS, Bengaluru.

Each tooth size dimensions were taken from the reference values described by Wheeler's (Table 1). ${ }^{4}$

\section{Software}

- Microsoft Windows 2000

- AutoCAD 2002

- Pro/Engineer V ersion 2001-3D-geometric modelling

- Hypermesh Version 5.0-finite element meshing

- Ansys V ersion 7.0 - finite element analysis

\section{Finite Element Modeling}

Numerical representation of the geometry was created by dividing the geometry into finite number of elements and the elements were connected together with nodes at the junction.

\section{Steps Involved in the Finite Element Modeling}

- CT scan of mandibular specimen: CT scan images of the mandible with dentition were taken at $1 \mathrm{~mm}$ intervals in parallel horizontal planes (Figs 1 and 2).

- Tracing the scanned picture: The scanned images were viewed with the DICOM software. Then theimages were copied and pasted in modeling software AutoCAD to trace the images of second premolar and first molar of each slice.

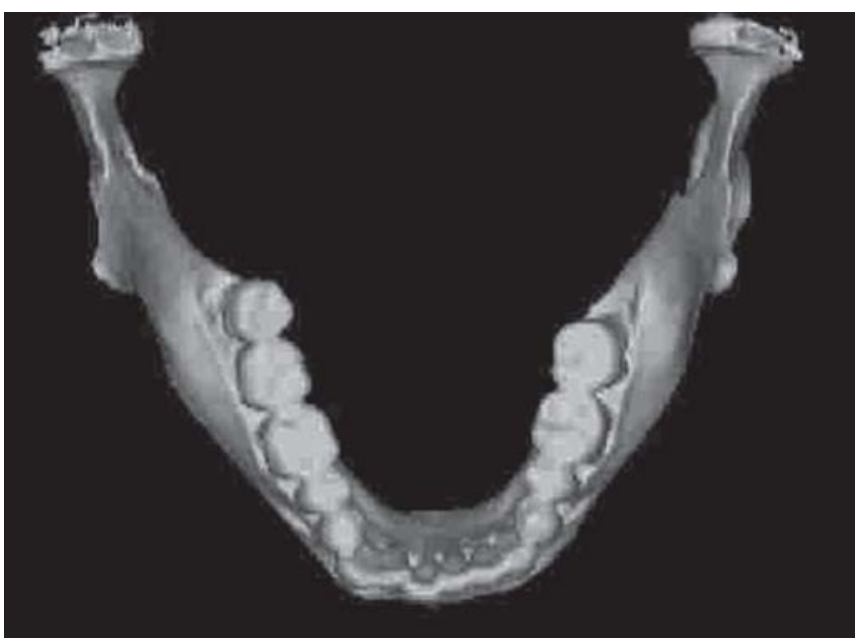

Fig. 1: CT scan image of mandible-occlusal view

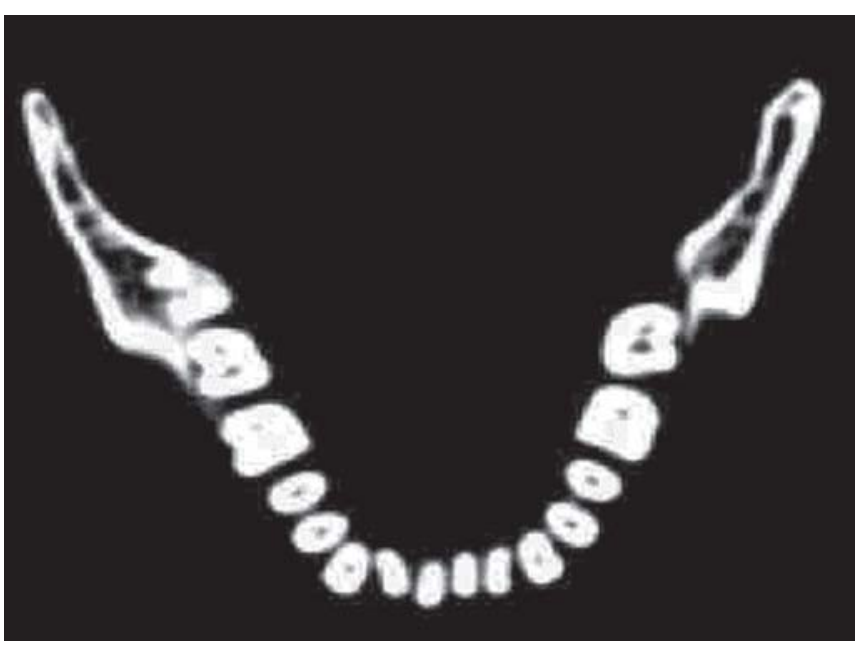

Fig. 2: CT scan images of mandible-cross-section $1 \mathrm{~mm}$ occlusal view

- Assembling the traces of the slices: The traces taken from the scanned picture were assembled in axial direction to get the complete set of traces into a single unit using modeling software Pro/Engineer.

- Creating geometric model: The assemblies of traces were brought into finite element analysis software package A nsys $V$ ersion 7.0. Then the areas and volumes were created from the traces of the second premolar and first molar including periodontal ligament and alveolar bone (Fig. 3).

\begin{tabular}{lcccccc} 
& \multicolumn{2}{c}{ Table 1: Measurements of the mandibular teeth: Average size in millimeters } \\
\hline Tooth & $\begin{array}{c}\text { Length of } \\
\text { the crown }\end{array}$ & $\begin{array}{c}\text { Length of } \\
\text { the root }\end{array}$ & $\begin{array}{c}\text { Mesiodistal } \\
\text { diameter of } \\
\text { crown }\end{array}$ & $\begin{array}{c}\text { Mesiodistal } \\
\text { diameter at } \\
\text { cervix }\end{array}$ & $\begin{array}{c}\text { Labio- or bucco- } \\
\text { lingual diameter } \\
\text { of crown }\end{array}$ & $\begin{array}{c}\text { Labio- or bucco- } \\
\text { lingual diameter } \\
\text { at cervix }\end{array}$ \\
\hline Central incisor & 9.0 & 12.5 & 5.0 & 3.5 & 6.0 & 5.3 \\
Lateral incisor & 9.5 & 14.0 & 5.5 & 4.0 & 6.5 & 5.8 \\
Canine & 11.0 & 16.0 & 7.0 & 5.5 & 7.5 & 7.0 \\
First premolar & 8.5 & 14.0 & 7.0 & 5.0 & 8.0 & 6.5 \\
Second premolar & 8.0 & 14.5 & 7.0 & 5.0 & 10.5 & 7.0 \\
First molar & 7.5 & 14.0 & 11.0 & 9.0 & 10.0 & 9.0 \\
Second molar & 7.0 & 13.0 & 10.5 & 8.0 & & 9.0 \\
\hline
\end{tabular}




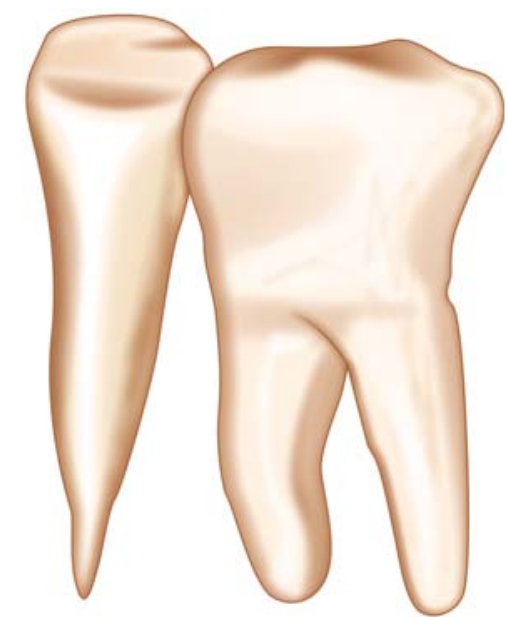

Fig. 3: 3D geometric model of second premolar-first molar

The 3D geometric model of mandibular dentition (14 teeth) was created using reference values of each tooth size described by Wheeler (Figs 5 and 6). ${ }^{4}$ The $3 \mathrm{D}$ set-up model was constructed in the microcomputer assuming a case of constriction.

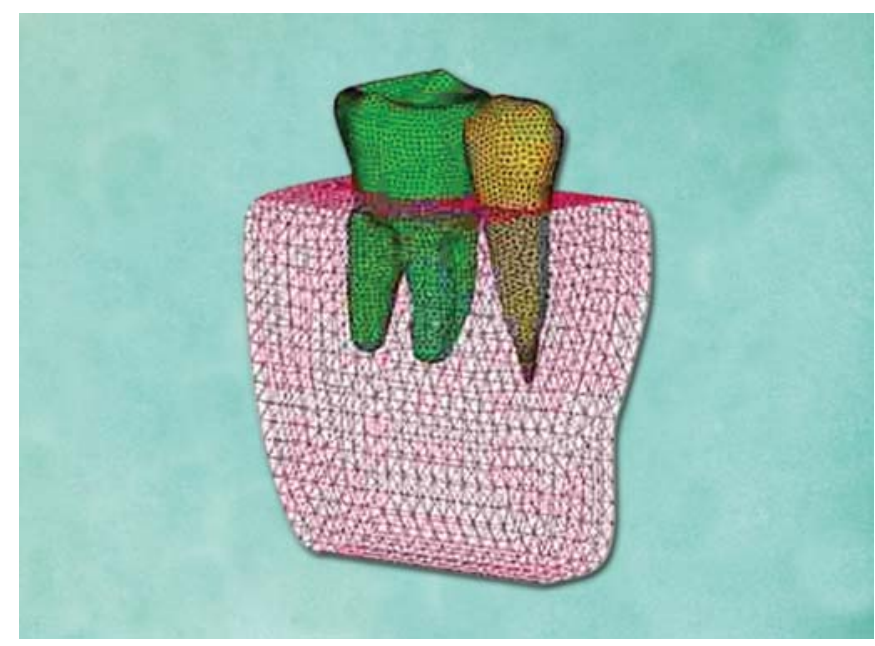

Fig. 4: Finite element model of second premolar-first molar

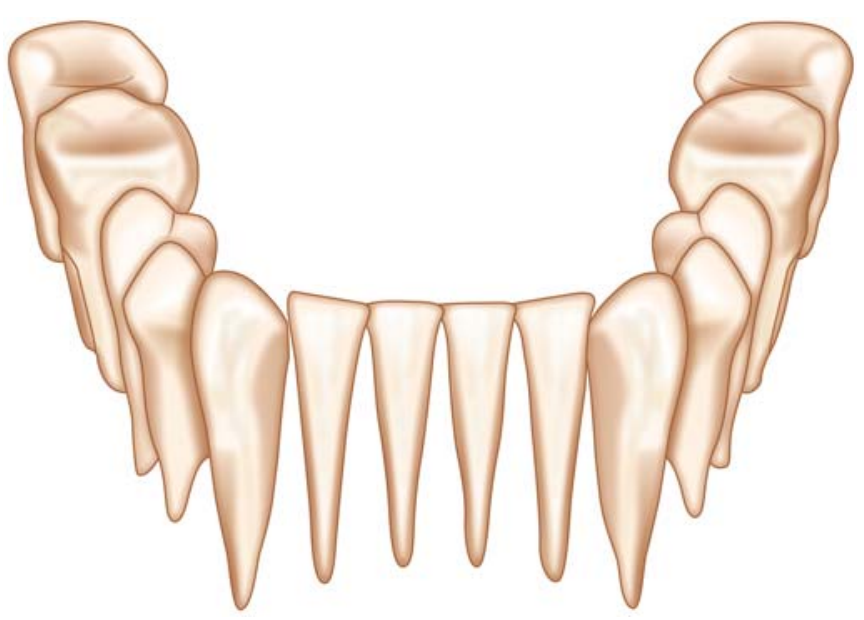

Fig. 5: 3D geometric model of mandibular teeth-anterior view
- Conversion of the geometric model to finite element model: These geometric models were converted into finite element models using Hypermesh version 5.0 (Fig. 7). The element shape that was described in the model was tetrahydron in form. These elements were connected to adjacent elements with the help of nodes, which join these elements in all directions. In order to establish the natural anatomy, the teeth were connected to the surrounding alveolar bone through the periodontal ligament in case of second premolar-first molar model (Fig. 4).

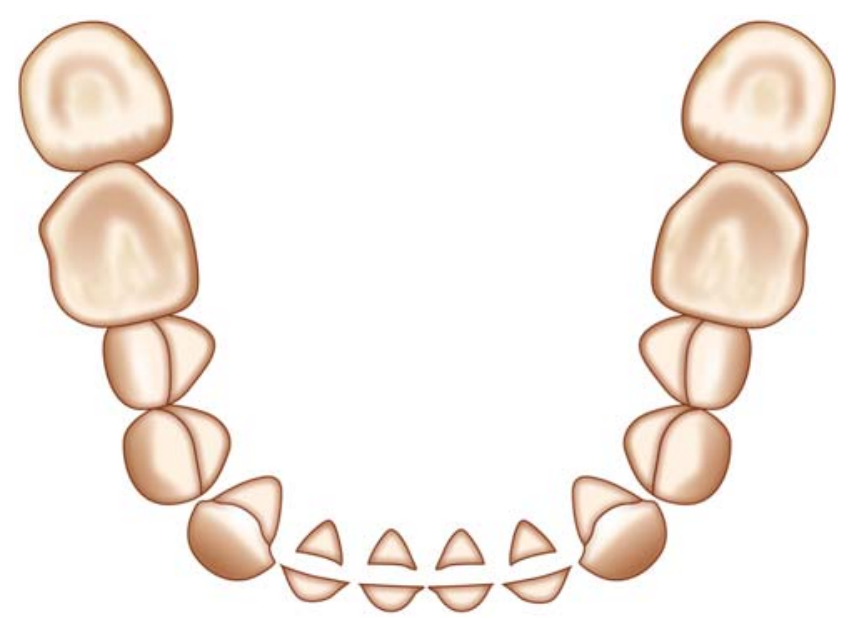

Fig. 6: 3D geometric model of mandibular teeth-occlusal view

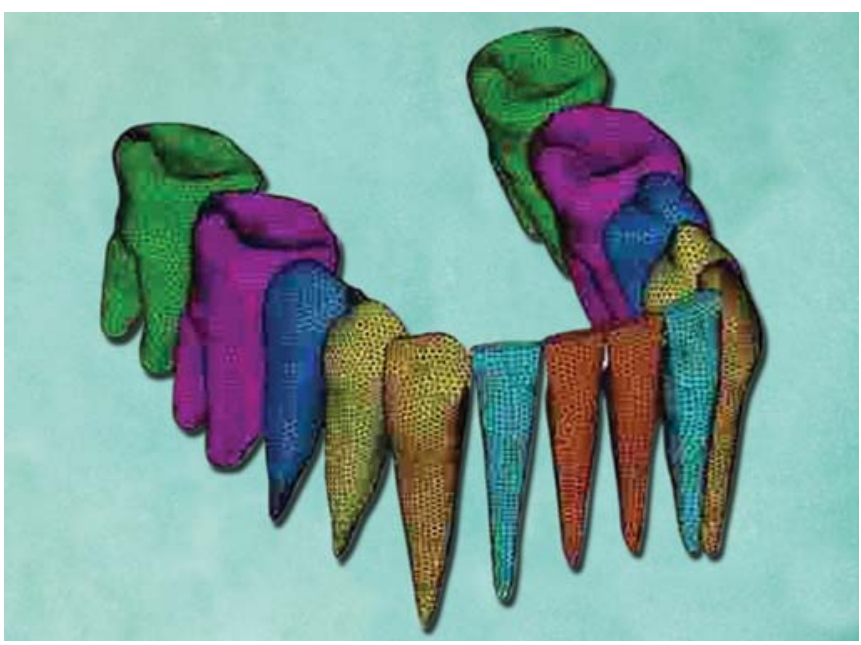

Fig. 7: FEM meshing of the mandibular arch-oblique view

A II the mandibular teeth in the arch were al so meshed with tetrahydral solid elements. A II the materials in the models were assumed to be isotropic and elastic (Table 2).

- M aterial property data representation (Table 3).

- Defining the boundary conditions: The boundary condition in the finite element model basically represents the load imposed on the structures under study and their 
An Experimental Study of Arch Perimeter and Arch Width Increase with Mandibular Expansion: A Finite Element Method

\begin{tabular}{|lrr}
\hline \multicolumn{3}{|c}{ Table 2: Elements and nodes } \\
\hline Finite element meshing & Elements & Nodes \\
\hline $\begin{array}{l}\text { Mandibular second premolar-first } \\
\text { molar + PDL + alveolar bone model } \\
\begin{array}{l}\text { Mandibular dentition (14 teeth) } \\
\text { (central incisor to second molar) }\end{array}\end{array}$ & 17912 & 9143 \\
\hline
\end{tabular}

\begin{tabular}{lcc}
\multicolumn{3}{c}{ Table: 3 Material properties of tooth, alveolar bone and } \\
periodontal ligament
\end{tabular}

fixation counterparts. The model was restrained at the inferior border of the mandible in order to avoid any motion against the loads imposed on the dentoalveolar structures.

The3D-simulation finite elementmodel of mandibular dentition was created using the average values.

- Application of forces: The A nsys version 7.0 was used to cal culate the strains and displacements at each nodal point. Expansion forces of $0.5 \mathrm{~N}$ and $5 \mathrm{~N}$ were used for the premolar and molar respectively, to be parallel to the occlusal plane supposing a pure horizontal force . The convergence point of the perpendicular lines to the displacement vector at nodal points of the first molar was calculated as the center of rotation. ${ }^{5}$

Following simulation of mandibular arch, rotational movement was induced in the buccal segment, from first premolar to second molar, in the 3D model around the location of centre of rotation derived from the FEM. The 3D simulation regarded canine to canine in the model as an immovable segment. L ateral expansion was produced by uprighting the buccal segment $10^{\circ}$ laterally around the centre of rotation. ${ }^{6}$

- Interpretation of the results: An opening of space between the canine and first premolar was regarded as an increase in dental arch perimeter. The relationships among the increase in arch width, perimeter, and changes in tooth inclination were also considered. ${ }^{6}$

\section{RESULTS}

The displacements at the first molar level obtained from the FEM (Fig. 8). The center of rotation was located $4.3 \mathrm{~mm}$ below the root apex of the first molar (Table 4).

The changes of tooth inclination during mandibular expansion (Table 5).

The result also showed $4.2 \mathrm{~mm}$ of unilateral expansion with $10^{\circ}$ of uprighting at the center of rotation $(4.3 \mathrm{~mm}$ below root apex of first molar).

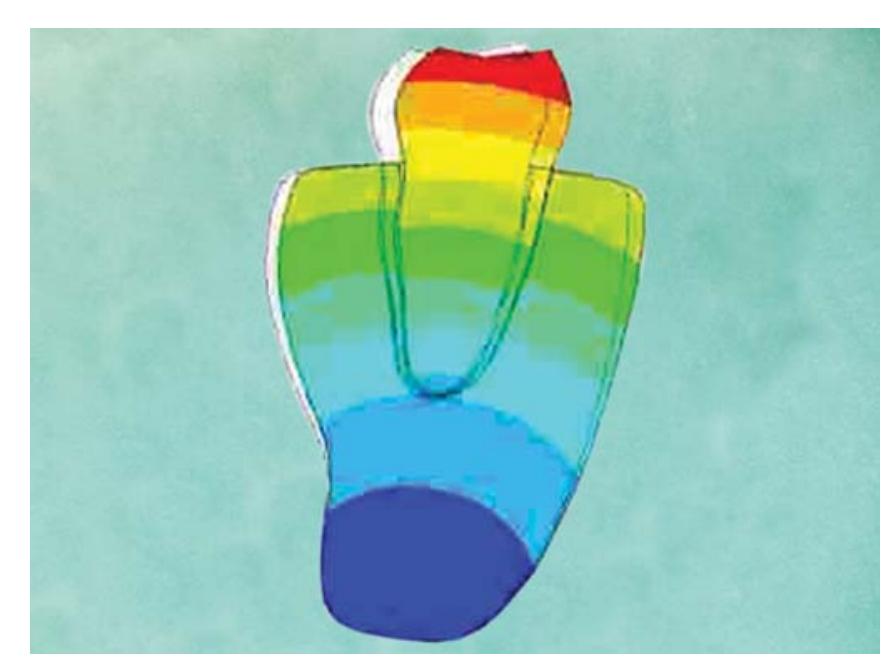

Fig. 8: Results of displacements at first molar derived from 3D FEM

\begin{tabular}{|c|c|c|c|}
\hline \multicolumn{4}{|c|}{ Table 4: Center of rotation } \\
\hline Tooth & Force & $\begin{array}{l}\text { Displacement } \\
(\mathrm{mm})\end{array}$ & Center of rotation \\
\hline $\begin{array}{l}\text { Second } \\
\text { premolar } \\
\text { First molar }\end{array}$ & $\begin{array}{l}0.5 \mathrm{~N} \\
5.0 \mathrm{~N}\end{array}$ & $\begin{array}{l}X=0.186 \\
Y=-0.01\end{array}$ & $\begin{array}{l}4.3 \mathrm{~mm} \text { below the } \\
\text { root apex of first } \\
\text { molar }\end{array}$ \\
\hline
\end{tabular}

Table 5: Results obtained after $10^{\circ}$ lateral expansion of mandibular buccal segment (in millimeters)

\begin{tabular}{lccc}
\hline Dimensional changes & Unilateral & Bilateral & Total \\
\hline Arch width at molar region & 4.2 & 8.4 & 8.4 \\
Arch perimeter & 1.3 & 2.6 & 2.6 \\
\hline
\end{tabular}

Thus, for every $1 \mathrm{~mm}$ of expansion there was $2.3^{\circ}$ of changes in the tooth axis inclination.

\section{DISCUSSION}

The FEM is a highly precise technique used to analyze structural stress. With its application in engineering for years, this method uses the computer to solve large number of equations to calculate stress on the basis of the physical properties of structures being analyzed. FEM has many advantages over the other methods (such as the photoelastic method), highlighted by the ability to include heterogenicity of tooth material and irregularity of the tooth contour in the model design and the relative ease with which loads can be applied at different directions and magnitudes for a more complete analysis. Finite element analysis has been used in dentistry to investigate a wide range of topics, such as the structure of teeth, biomaterials and restorations, dental implants and root canals. ${ }^{7}$

The position of mandibular dentition may be influenced by the maxillary skeletal morphology. Mandibular arch widening is primarily due to decompensation and an 
uprighting of the mandibular posterior teeth, which often erupt into occlusion in a more lingual orientation because of associated constricted maxilla.

In a similar study by $\mathrm{W}$ alter, ${ }^{8}$ states that mandibular arch width could be expanded permanently.

W arren $\mathrm{Hamula}^{9}$ stated that the mandibular arch expansion has been positively applied clinically.

Few attempts have been made to quantify the changes in arch perimeter associated with increase in arch width despite its interest and clinical usefulness.

The present study intended to assess three-dimensionally, the increase in arch perimeter and arch width associated with mandibular expansion along with tooth inclination. For this purpose, a 3D FEM was performed.

In this study CT scan of the Indian mandiblular skeleton specimen was used, which was taken at $1 \mathrm{~mm}$ intervals in the parallel horizontal planes to enable high geometric accuracy. These slices were transfered to AutoCAD and each slice was superimposed to form 3D geometric model.

A similar study was conducted by Faruk et al. ${ }^{9}$ in which they took CT scan of the mandible at $1 \mathrm{~mm}$ in horizontal plane, then transfered to A utoCAD and superimposed. They performed mandibular distraction in the middle intersection point on mandibular symphysis.

A nother study was carried out by $M$ itsuru M otoyoshi et al. ${ }^{6}$ In their study they used mandiblular CT scan at $1 \mathrm{~mm}$ and these $\mathrm{CT}$ slices were digitized with microcomputer and converted into geometric model.

\section{Center of Rotation}

In the present study the expansion forces of $0.5 \mathrm{~N}$ and $5 \mathrm{~N}$ were applied on the 3D finite element model of mandibular second premolar and first molar, respectively, having 17912 elements and 9143 nodes, parellel to occlusal plane supposing pure horizontal force at the middle of the crown from the lingual side. The result showed that there was displacement in $\mathrm{x}$-axis by $+0.186 \mathrm{~mm}$ and in $\mathrm{y}$-axis by $0.01 \mathrm{~mm}$. The convergence point of the perpendicular lines to this displacement vector was calculated as the center of rotation, which was found at $4.3 \mathrm{~mm}$ below the root apex of first molar. ${ }^{10}$.

Similar study was conducted by M itsuru M otoyoshi et $\mathrm{al}^{6}$ in which they found the center of rotation at $4.5 \mathrm{~mm}$ below the root apex of first molar. This is in accordance with our study.

Direct comparision can be made, only with the study conducted by $M$ itsuru $M$ otoyoshi et al ${ }^{6}$ as there were no other studies being performed using same method.

\section{Arch Perimeter vs Arch Width}

In our study the 3D simulation finite element model was performed of the mandibular dentition (14 teeth) using average reference values from Wheeler's, assuming a constricted arch. The canine to canine in the model was regarded as immovable segment (Fig. 9). 3D aspects of tooth movement associated with expansion was evaluated, and an opening space between canine and first premolar on the $3 \mathrm{D}$ set-up simulation was regarded as an increase in dental arch perimeter. The $10^{\circ}$ lateral expansion was applied to the lower buccal segment at the centre of rotation found at $4.3 \mathrm{~mm}$ below the root apex of first molar. The result showed a space of $1.3 \mathrm{~mm}$ between the canine and first premolar, and thus an increase in arch perimeter by $2.6 \mathrm{~mm}$ (Fig. 10).

The tip of the mesiolingual cusp of the first molar moved $4.2 \mathrm{~mm}$ laterally when $10^{\circ}$ of lateral expansion was applied to the lower buccal segment at the center of rotation found at $4.3 \mathrm{~mm}$ below the root apex of first molar, thus resulting a change in intermolar width of $8.4 \mathrm{~mm}$ (Fig. 10). These

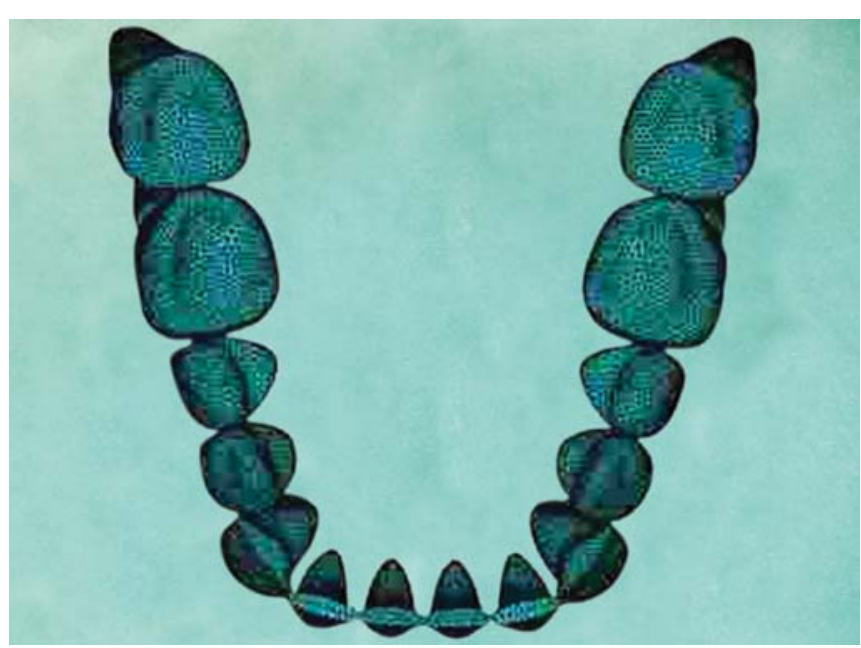

Fig. 9: Mandibular arch before expansion

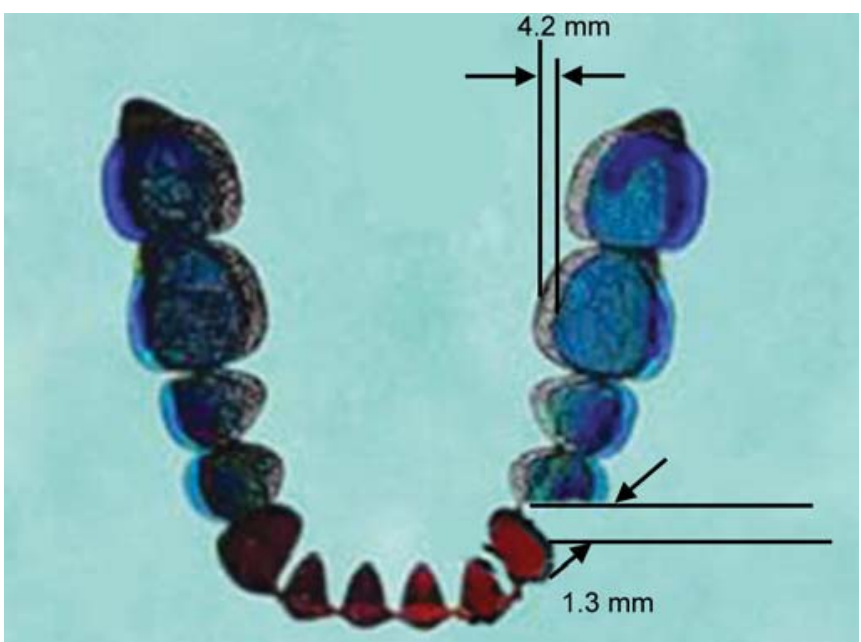

Fig. 10: Mandibular arch-superimposition before and after lateral expansion 
An Experimental Study of Arch Perimeter and Arch Width Increase with Mandibular Expansion: A Finite Element Method

values mean that $1 \mathrm{~mm}$ of intermolar expansion- increases the perimeter by $0.30 \mathrm{~mm}$.

The 3D simulation showed that a $1 \mathrm{~mm}$ increase in intermolar width resulted in an increase in arch perimeter of $0.30 \mathrm{~mm}$, indicating a greater value than that derived by Germane et al. ${ }^{11} \mathrm{He}$ compared quantitatively the effects of expansion on mandibular arch perimeter using a mathematical model. He modeled the mandibular arch form with a two-dimensional spline function in order to calculate changes in arch perimeter associated with mandibular expansion. ${ }^{11}$ According to the mathematical model developed by the author, a $1 \mathrm{~mm}$ increase in intermolar width results in an increase in arch perimeter of only $0.27 \mathrm{~mm}$. This difference in arch perimeter might be due to the different geometric model used. The 3D finite element model was used in our study in place of 2D mathematical model used by the author. ${ }^{11}$

A nother similar experimental study conducted by $M$ itsuru et al ${ }^{6}$ on mandibular expansion showing an increase in arch width and perimeter using 3D FEM , concluded that $1 \mathrm{~mm}$ increase in intermolar expansion increased the perimeter by $0.37 \mathrm{~mm}$. In their study there was an increase of $2.86 \mathrm{~mm}$ of arch perimeter and $7.76 \mathrm{~mm}$ of intermolar width, when $10^{\circ}$ of lateral expansion was applied to the lower buccal segment at the center of rotation $4.5 \mathrm{~mm}$ below the root apex of first molar. This is in agreement with our study.

\section{Tooth Axis Inclination}

In the present study when $10^{\circ}$ of lateral expansion was applied to the lower buccal segment at the center of rotation (found at $4.3 \mathrm{~mm}$ below the root apex of first molar), there was a $4.2 \mathrm{~mm}$ of increase in intermolar width unilaterally.

So, 3D simulation showed that a $1 \mathrm{~mm}$ increase in unilateral arch width results in tooth inclination of approximately $2.3^{\circ}$.

A simlar experimental study conducted by Mitsuru et al ${ }^{6}$ showed $2.6^{\circ}$ of changes in tooth axis inclination. In their study there was a $3.38 \mathrm{~mm}$ of increase in unilateral arch width, when $10^{\circ}$ lateral expansion was applied to the lower buccal segment at the centre of rotation found at $4.5 \mathrm{~mm}$ below the root apex of first molar. This is in agreement with our study.

The results from our study show that, expansion could be useful in avoiding removal of teeth in borderline cases, whereas it may not be sufficient in severe crowding cases.

\section{CLINICAL SIGNIFICANCE}

One should be aware that the structural and spatial relationships of various dentofacial components vary among the individuals. It is important to realize that these factors may contribute to varied responses of the dentoskeletal components on loading thus affecting the locations of the center of rotation. The result of this study is valid only for a single specific human skull.

As the FEM evolves and scientists are able to more clearly define physical properties of biological tissues, more accurate information can be generated at the level that other analytical methods cannot fully provide data.

This result would be of value clinically for prediction of the effects of mandibular expansion.

Future clinical studies are necessary to validate the findings of this study.

\section{CONCLUSION}

The following conclusions were drawn from this study:

- Three-dimensional simulation showed that $1 \mathrm{~mm}$ of intermolar expansion increased the arch perimeter by $0.30 \mathrm{~mm}$.

- The arch width increased by $4.2 \mathrm{~mm}$ with $10^{\circ}$ of lateral expansion unilaterally.

- A $1 \mathrm{~mm}$ increase in unilateral arch width resulted in a change in tooth inclination of approximately $2.3^{\circ}$.

From these conclusions it can be considered that, the gain in arch perimeter with mandibular expansion could be beneficial in borderline cases to treat them by nonextraction means.

\section{REFERENCES}

1. A dkins M D, Nanda RS, Currier GF. A rch perimeter changes on rapid palatal expansion. A m J Orthod Dentofac Orthop 1990;97:194-99.

2. Woods MG. M andibular arch dimensional and positional changes in late mixed-dentition class I and II treatment. A m J Orthod Dentofac Orthop 2002;122:180-88.

3. L ee RT. A rch width and form: A review. A m J Orthod Dentofac Orthop 1999;115:305-13.

4. Wheeler RC. A $n$ atlas of tooth form (6th ed). WB Saunders Co. Philadel phia 1969: p.13.

5. Smith RJ, Burstone CJ. M echanics of tooth movement. A m J Orthod Dentofac Orthop 1984;85:294-307.

6. M otoyoshi M, Masayuki H, Takahisa S, Shinkichi N. A n experimental study on mandibular expansion: increases in arch width and perimeter. European J Orthod 2002;24:125-30.

7. Rudolph DJ, Willes M G, Sameshima GT . A finite element model of apical force distribution from orthodontic tooth movement. A ngle Orthod 2001;71:127-31.

8. W alter DC. C omparative changes in mandi bular canine and first molar widths. A ngle Orthod 1962;32:232-41.

9. Basciftci FA, Hassan HK, Haluk I, Siddik M. Biomechanical evaluation of mandibular midline distraction osteogenesis by using the finite element method. A m J Orthod D entofac Orthop 2004;125:706-15.

10. Tanne K, K oenig HA, B urstone CJ. M oment to force ratios and the center of rotation. Am J Orthod Dentofac Orthop 1988; $94: 426-31$. 
11. Germane N, Steven JL, Loretta KR, James HR, Robert JI. Increase in arch perimeter due to orthodontic expansion. A m J Orthod D entofac Orthop 1991;100: 421-27.

\section{ABOUT THE AUTHORS}

\section{Baswaraj (Corresponding Author)}

Reader, D epartment of Orthodontics, Dayananda Sagar College of D ental Sciences, B engaluru, K arnataka, India, e-mail: drbaswabidar@ gmail.com

\section{Hemanth}

Professor, Department of Orthodontics, Dayananda Sagar College of Dental Sciences, Bengaluru, Karnataka, India

\section{Jayasudha}

Reader, Department of Pedodontics, K GF College of Dental Sciences Kolar, Karnataka, India

\section{Chandrashekhargouda Patil}

Senior Lecturer, Department of Orthodontics, PDU Dental College Solapur, M aharashtra, India

\section{P Sunilkumar}

Professor, D epartment of Orthodontics, PDU D ental College, Solapur M aharashtra, India

\section{HP Raghuveer}

Principal, Professor and Head, D epartment of Oral and M axillofacial Surgery, Dayananda Sagar College of Dental Sciences, B engaluru K arnataka, India

\section{B Chandralekha}

Formerly Professor and Head, Department of Orthodontics Government Dental College, B engaluru, K arnataka, India 